\title{
I huvudet på en lärarutbildare i bild - om studenters reflektioner i sin foto- och filmprocess
}

Staffan Guttman

\section{Undervisning i stå!}

Följande artikel handlar om Grundlärare mot fritidshem med bild som estetisk inriktning. Efter examen blir studenter i program-met behöriga bildlärare upp till årskurs 6. Därför är programmet också inriktat mot skolan. Undervisningen i fotografi och film hade emellertid gått i stå! Det kändes som om jag hade hasat in till och ut från lektionerna utan att nå fram till ett synligt resultat. Tidsbrist var ett av tänkbara skäl för det ganska magra resultatet, att det alltså saknats tillräckligt med tid för att göra uppgifterna. Dags att ändra kursgången, tänkte jag! Dags att öka på kunskaperna om bildens betydelse i skolan. Alla lärare använder bild som redskap för att inspirera sina elever till kunskapsbildning. Det var ett viktigt motiv för att studera hur bilder kommunicerar, exempelvis genom användningen av olika informations- och kommunikationsteknologier, IKT. Det finns tydligt stöd för detta i styrdokumenten. Jag ville verkligen att studenterna skulle träna berättande med bilder, att få mer insikter om ljusets betydelse. Jag ville öka på deras kunskaper om dramaturgi och om komposition. Även tekniska kunskaper om kameran måste ses som viktigt. Vi hade pratat om allt detta på seminarierna och vi hade diskuterat vad bildspråk är. Men, det kändes som om invanda tankemönster och traditioner stod i vägen för detta under våra träffar. På seminarierna verkade studenterna i huvudsak se bilder ur ett formmässigt dekorativt synsätt. Visst finns sådana bildmässiga

Hur du refererar till det här kapitlet:

Guttman, S. 20I8. I huvudet på en lärarutbildare i bild - om studenters reflektioner i sin foto- och filmprocess. I: von Schantz, U., Thorgersen, K. and Lidén, A. (red.) De estetiska ämnenas didaktik Utmaningar, processer och protester. Pp. I67-I 79. Stockholm: Stockholm University Press. DOI: https:// doi.org/ıo.I6993/bap.l. License: CC-BY 
aspekter, men läroplanen föreskriver också kunskaper om de kommunikativa delarna som nödvändiga. Många lärare på fältet uttrycker tidsbrist som skäl för att inte kunna arbeta på ett sätt som de vill. Även jag har erfarenheten av tidsaspekten som ramfaktor för arbetet mot uppnåendemålen. Jag behövde nu redskap för att höra studenternas syn på sin utbildning och jag behövde testa nya idéer, testa mina frågor om ämnesdidaktiken. Nya grepp behövdes för att se bilden som även ett informativt medium.

\section{Fou-projektet}

Under denna period arbetade jag på Cehum, en avdelning under Institutionen för etnologi, religion och genus, Erg, Stockholms universitet. De estetiska ämnena var då temporärt placerade där. I tjänsteutövningen ingick också timmar för utveckling av utbildning, Forskning och utbildning, Fou. Läsåret 20I 5 startades ett projekt på institutionen, där vi lärarutbildare arbetade med en antologi inom ramen för Fou-tiden med artiklar om våra respektive erfarenheter som ämnesdidaktiker. Här såg jag nu en chans att få svar på de frågor som tagits upp ovan. Genom Fou-projektet ville jag undersöka möjligheterna för en revidering av den bildkursen som jag nämnt ovan. Vid samma tid ombildades vår institution till Institutionen för de humanistiska och samhällsvetenskapliga ämnenas didaktik, HSD, och antologiprojektet följde med till den nya institutionen. Jag såg fram mot att institutionsförändringen skulle innebära större utrymme för den estetiska ämnesdidaktiken

Jag gav kursen ökat fokus på kamerans och ljusets betydelse för kommunikation av visuella uttryck som når unga människor i skola och samhälle. ${ }^{\mathrm{I}}$ Kurslitteraturen reviderades för ett större fokus på visuell retorik, IKT och semiotik när det gäller innehållslig bildtolkning. För mig är teori en viktig del av det praktiska arbetet. Hur skulle jag nu få kunskaper om studenternas syn på den reviderade kursen? Hur skulle deras estetiska lärprocess synliggöras? Efter samtal med en kollega framställdes en processkarta i A3-format. Efter kursinslagen skulle studenterna ge sina utlåtanden om sina erfarenheter av inslaget (Bilaga I). Syftet var att ge svar på frågor om vad studenterna uppfattade som lätt alternativt svårt när det gäller att i tur och ordning komma på idé, planera 
och genomföra, samt utvärdera och redovisa sina arbeten. Tanken var främst att få uppgifter i formativ riktning om den estetiska lärprocessen. Vissa farhågor om processkartan fanns dock. Jag var rädd att uppgiften skulle kännas betungande, som en ytterligare en uppgift att fylla i den efter kursinslagen. Timmarna för ämnesdidaktik i de estetiska ämnena hade blivit allt färre genom åren och därför var jag inte helt övertygad om insamlingsmetodens tillförlitlighet, att processkartan skulle ge tillräckligt trovärdiga uppgifter. En del suckar och kommentarer skulle också höras i den riktningen. Men när jag efter avslutad kurs samlade uppgifterna om lärprocessen (Bilaga I) gav dessa snarare intrycket att processkartan upplevts meningsfull för studenterna. De verkade ha antagit uppdraget genom att diskutera och dokumentera sin bedömning.

\section{Studenternas synpunkter}

De inkomna svaren från processkartan tycktes alltså ge mer förhoppningar och mindre farhågor med insamlingsmetoden. Flera grupper uppgav det vara lätt att komma på idéer vid fotografering och filmning. Det var också lätt och roligt att se olika betydelser av bilder växa fram. Roligt och lätt att posera, filma och göra roller. En grupp uppgav att kursen varit lärorik och att det även varit givande att se hur analys kan göras, att tolkningar kan vara flera. Det tycker jag är intressant eftersom de teoretiska perspektiven varit nya för de flesta och att det förmodligen behövs tid för att se det meningsfulla med teori. Flera svar visade tecken på att kursupplägget och den estetiska lärprocessen varit beroende av hur studentlagen fungerat, vilket inte är så konstigt. För de allra flesta verkar ändå kursen ha främjat upplevelser av typen "Roligt! Lärorikt! Riktigt kul på vägen.”

Mer komplicerat har det dock varit att komma vidare efter att ha fått idéer; att skriva fram planering, att pröva tekniker och att slutföra foto och filmning med ett tänkt budskap. Det är naturligt, tänkte jag, eftersom kursen handlar om just detta och borde vara en av utmaningarna. Det är heller inte konstigt att det känts svårt att redovisa muntligt. De allra flesta av studenterna har saknat sådana erfarenheter. När det gäller de teoretiska 
perspektivens betydelse för uttolkning, verkar detta helt naturligt ha känts meningsfullt för vissa och förvirrande för andra. Jag ser det som en tidsfråga innan tillämpbarheten upplevs som meningsfull. Därför är det viktigt att teorin löper längs med kursen. Tidsaspekten: Som jag misstänkte har flera studentlag uppgett bristande tid som begränsning för att slutföra arbeten, för lite tid till planering, genomförande och redovisning.

Andra tänkvärda synpunkter på kursen är att introduktionerna till inslagen har uppfattats väl långa och att feedback för fotoinslaget borde förstärkas. Grupparbetena verkar för en del studentlag ha fungerat väl svajigt. Rådet från en grupp var därför att lärarna skulle "schemalägga planering”, alltså att schemalägga den tiden som gruppen har för planering. Här har jag en invändning! Studenterna själva borde kunna lägga upp planering med alla gruppmedlemmars som deltagare. Jag har tidigare erfarenheter av gruppers samarbetssvårigheter inom lärarutbildningen. Det finns säkert flera förklaringar. En kan vara att många studenter arbetat vid sidan om studierna och får allt mindre med tid för detta. En annan att en del studenter går parallella studiegångar. Hur som helst verkar alltså schemaläggning av gruppernas egen planering i min undersökning ses som ett redskap för samarbetet inom teamen. Ytterligare en idé för att stötta teamkänslan är att arbeta med deltagarkontrakt. Det har jag gjort i tidigare kurser med positivt resultat.

\section{Lätt att komma på idéer - svårare att komma vidare}

Sammanfattningsvis ser den förändrade kursgången ut att ha främjat förväntade studieresultat, som att kunna orientera sig i hanteringen av modern teknik i bildskapande processer genom IKT och att diskutera dess roll som pedagogiskt och kommunikativt verktyg. Även då att kunna identifiera, diskutera, och med ämnesrelevanta begrepp beskriva och stödja den gestaltande lärprocessen samt reflektera kring bilddidaktiska frågeställningar i fritidshem och skola. Det syns i svar som "... lätt att komma på idéer vid fotografering och filmning" och lätt och roligt för flera att posera, filma och göra roller. Sen har det också varit "... lätt och roligt att se hur olika betydelser (av visuella uttryck) växt fram”. 
Tolkning av visuella uttryck verkar ha känts meningsfullt. Det är verkligen inspirerande för mig som kurslärare att ta del av, bland annat med tanke på svårigheter en del av studenterna haft att reflektera analytiskt på varandras produktioner. ${ }^{2}$ Kursupplägget verkar ha upplevts som gott. Jag ser detta som exempel på att planeringen genom de teoretiska infallsvinklarna varit adekvat. Exempel på detta är uttalandet "Roligt! Lärorikt! Riktigt kul på vägen".

Synpunkterna på introduktioner och mer feedback på fotoinslaget, som några team har uppgett, kan justeras genom kortare intron av inslagen samt att förbereda ytterligare tid för feedback på exempelvis fotoinslaget. Det syns också ett behov att stärka teamkänslan. En idé är att göra det visuellt, till exempel genom grupporträtt av deltagarna i teamen. Tidsramarna verkar helt förståeligt ses som begränsning i kursen. Det behövs mer tid för att uppnå kursmålen.

Gällande synen på den estetiska lärprocessen verkar metoden, processkartan, ha fungerat som ett inslag i sig. Detta gick i motsatt riktning mot mina farhågor. Atmosfären under lärandeprocessen har mestadels känts positiv också för mig som kurslärare. Fast visst, har också jag känt av en viss stumhet i responsen hos de studerande vid mina något långa introduktioner. Detta har jag nu möjlighet att justera vid planering av nästa kurs.

Svaren från studenterna har styrkt mig i tron att arbete med de teoretiska delarna ska löpa parallellt med de praktiska övningarna. Det tar tid att se teori som ett meningsfullt redskap i det praktiska arbetet i skolorna. De teoretiska infallsvinklarna visuell retorik, IKT och semiotik har visat sig användbart som struktur i kursupplägget.

\section{Mer bild i skolan}

Många lärare önskar sig som sagt mer tid i skolan. De estetiska ämnena har fått de kraftfullaste åtstramningarna. I läroplanen finns det samtidigt tydliga mål när det gäller bildens och IKT:s betydelse för unga människors växande till demokratiska individer. Naturligtvis borde bildämnet tillsammans med IKT få fler timmar. För att möta behovet av mer kunskaper behövs fler 
timmar per kurs i de estetiska ämnena på lärosätet. Med låt säga dubbelt så många timmar per kurs skulle detta möjliggöra en fördjupning av samarbetet mellan verksamhet och lärosäte, vilket också skulle förstärka det formativa arbetet mot en tydligare pedagogisk användning genom bedömning för lärande. ${ }^{3}$ Betänk att studenterna som ingått i min undersökning, Grundlärare mot fritidshem och skola, efter fullgjord utbildning blir behöriga att sätta betyg i årskurser upp till 6:an. Mer tidsutrymme skulle hjälpa dessa kommande lärares förståelse för skolelevers kunskaper om betydelsen av bild och IKT. Samarbetet mellan lärosäte och verksamhet skulle samtidigt ske i högre utsträckning, vilket också borde underlätta ämnesövergripande insatser. Lundahls tes bedömning för lärande, inte endast av lärande, skulle realiseras genom mer holistiskt präglade bedömningsstrategier. ${ }^{4}$ Feeback for Feed Forward, är ett uttryck för detta. Genom ett flertal års VFU-besök har jag goda erfarenheter av den ömsesidiga kontakten mellan lärosäte och verksamheten i skolorna. Det tycks finnas ett positivt och jag tycker naturligt samband mellan ämnesdidaktik i bild och förståelsen för behovet av ämnet bild i skolan. Här följer några grepp jag skulle vilja arbeta vidare med vid ett ökat antal timmar i ämnesdidaktiken i bild:

Medvetenhet och bedömning hänger ihop! Jag vill att studenterna ska förstå sina egna bedömningsaspekter av visuella uttryck. Det är därför viktigt att göra sig medveten om dessa aspekter och även att se det meningsfulla i att testa olika tolkningar av samma bilder. Därför är det också viktigt att kontinuerligt träna det analytiska tänkandet. Jag har använt litteraturen som hjälp till kursupplägget. I min lilla undersökning tycks det som sagt finnas ett samband mellan en tydlig kursstruktur och ett meningsfullt lärande. Teoretiska aspekter som semiotik, visuell retorik och kunskaper om IKT kan användas som redskap att hänga upp lärandet på och även att återkoppla senare i studenternas utbildning mot arbetet som grundlärare i fritidshem och skola. Processkartan ger uttryck för detta i "Roligt! Lärorikt! Riktigt kul på vägen.”

Ljus talar till ett av våra fem sinnen, synen. Undervisningen i fotografi och film skulle berikas med mer innehåll av ljusets betydelse för dramaturgi och tolkning av bilder i olika miljöer. Varför? Jo, kunskaper om ljus är en viktig förutsättning för att undervisa 
elever i att förstå bilder och att locka dem till lärande. En viss belysning kan förstärka dramatiken i ett porträtt. En annan belysning kan i stället ge en lugn atmosfär. Insikter om detta borde ge både studenter och skolelever större förståelse för hur bilder väljs ut för olika ändamål i massmedier.

När det gäller workshops och det praktiska arbetets betydelse för lärandet vill jag naturligtvis undervisa om hur och varför man fotograferar, men också hur man låter sig fotograferas? Hur ska jag stå och röra mig inför en fotografisk stillbildssession? Hur spelar jag en trovärdig roll ur ett manus inför kamera genom rörlig bild? En idé är att föreställa olika lärartyper. Kliva in i olika roller. Som alla människor spelar också läraren roller, lärarroller. Läraryrket är först och främst ett offentligt uppdrag. För att väcka elevers intresse måste läraren sätta sig in i lärarrollens betydelse. Ibland hörs från yrkesverksamma lärare att en person äger en speciell begåvning för att undervisa. Kanske är det så, men jag tror också att man kan träna se sin egen begåvning och träna sig till ett självförtroende till en trovärdig lärarroll.

\section{Bilaga 1. Studenters reflektioner kring sin foto- och filmprocess}

Fotoinslag

Sammantaget för elva smågrupper med aspekterna i kronologisk tidsmässig ordning.

Tabellens information om fotoinslaget i löpande text

Det var lätt att tillsammans komma på idéer och planera för uppdraget. Lätt och roligt att under genomförandet se olika betydelser av bilder växa fram. Likaså att delegera och turas om med olika arbetsuppgifter. Även posera uppgavs vara lätt. Också gällande utvärderingen och redovisningen av kursinslaget uppgavs bildens betydelser genom tolkning vara lärorikt att ta del av. Detta kunde göras genom arbetet med att sätta sig in i andras tolkningar av egna bilder.

Det var svårt att komma igång med idéerna och hitta en röd tråd samt finna på budskap. Tidsramarna för planering kursinslaget borde ha varit större. Gällande genomförandet tyckte någon grupp det var svårt med tekniken, bland annat när det gäller att 


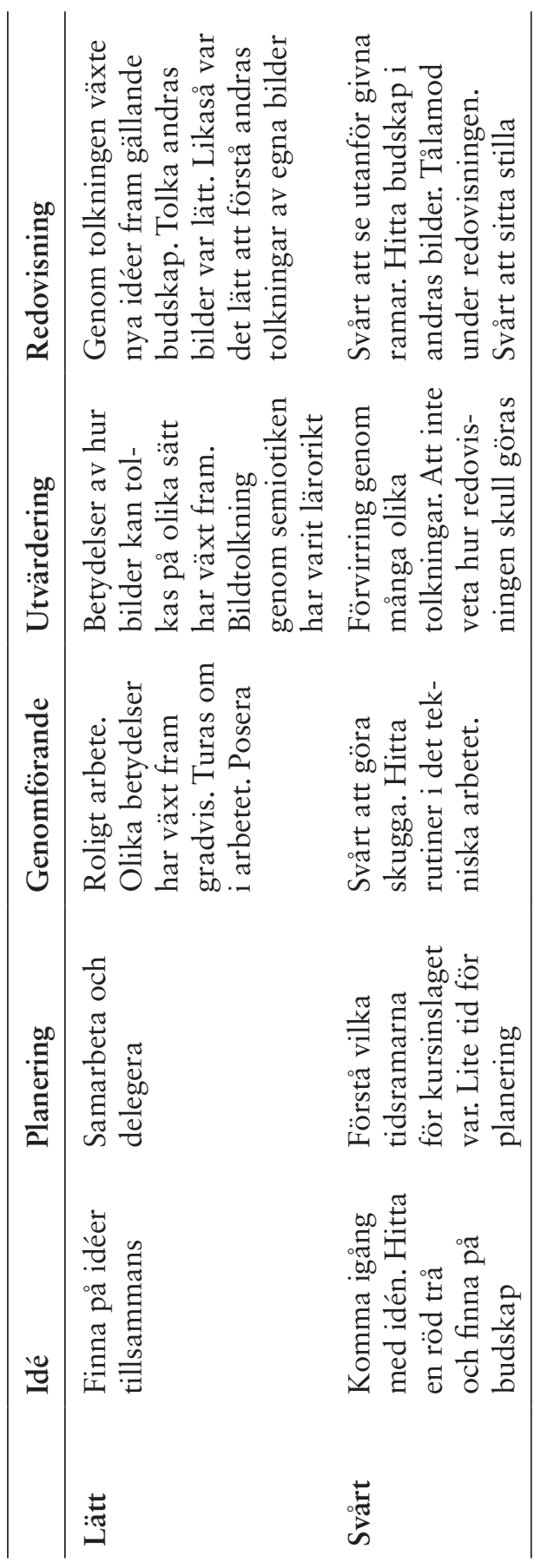




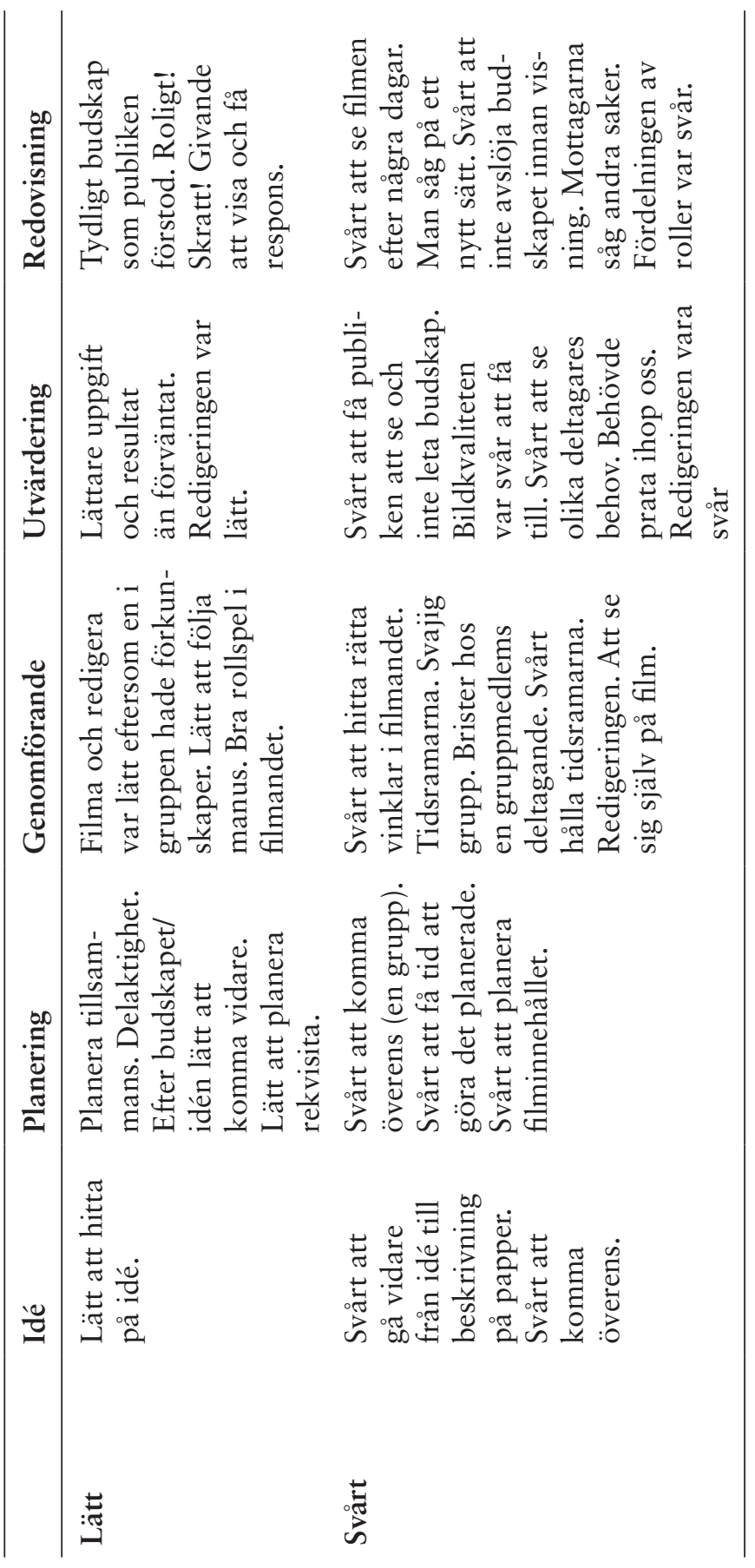


göra skugga. Vid utvärderingen av kursinslaget uppgav en grupp förvirring genom att det verkade finnas ett stort tolkningsutrymme. Vidare svårt att veta hur redovisningen skulle ske och att se utanför givna tankeramar. Tålamod under redovisningen och svårt att sitta stilla.

\section{Filminslag}

Sammantaget för elva smågrupper med aspekterna i kronologisk tidsmässig ordning.

Tabellens information om filminslaget i löpande text

Det var lätt att hitta på idéer. Lätt att planera tillsammans. God delaktighet. Efter att ha funnit på budskap/idé var det lätt att komma vidare. Lätt att planera rekvisita. Genomförande: filma och redigera var lätt eftersom en i gruppen hade förkunskaper. Lätt att följa manus. Bra rollspel i filmandet. Filmuppgift och resultat var lättare än förväntat. Också redigeringen var lätt för denna grupp. Vid redovisningen blev budskapet tydligt som publiken kunde förstå. "Rolig! Skratt! Givande att visa och få respons."

Det var svårt att komma vidare från idé till beskrivning på papper. Svårt också att komma överens för en grupp. Också vid planeringen av arbetet var det svårt att komma överens uppger deltagarna i samma grupp. Svårt då även att få tid att planera filminnehållet. Genomförande: Svårt att hitta rätta vinklar i filmningen. Tidsramarna vara svåra att hålla. En grupp reflekterar över att sammanhållningen i deras filmteam varit svajig. Det fanns brister i en av deltagarnas delaktighet. Redigeringen var svår. Också svårt att se sig själv på film. Vid utvärderingen var det svårt att få publiken att se och inte leta budskap. Bildkvaliteten var svår att få till. Också svårt att se olika deltagares behov. "Vi behövde prata ihop oss." Svårt sen att se filmen efter några dagar. Man såg på ett nytt sätt. Svårt att inte avslöja budskapet innan visning. Fördelningen av roller var svår.

\section{Hela kursen}

Sammantaget för elva smågrupper med aspekterna i kronologisk tidsmässig ordning.

Tabellens information om hela kursen i löpande text 


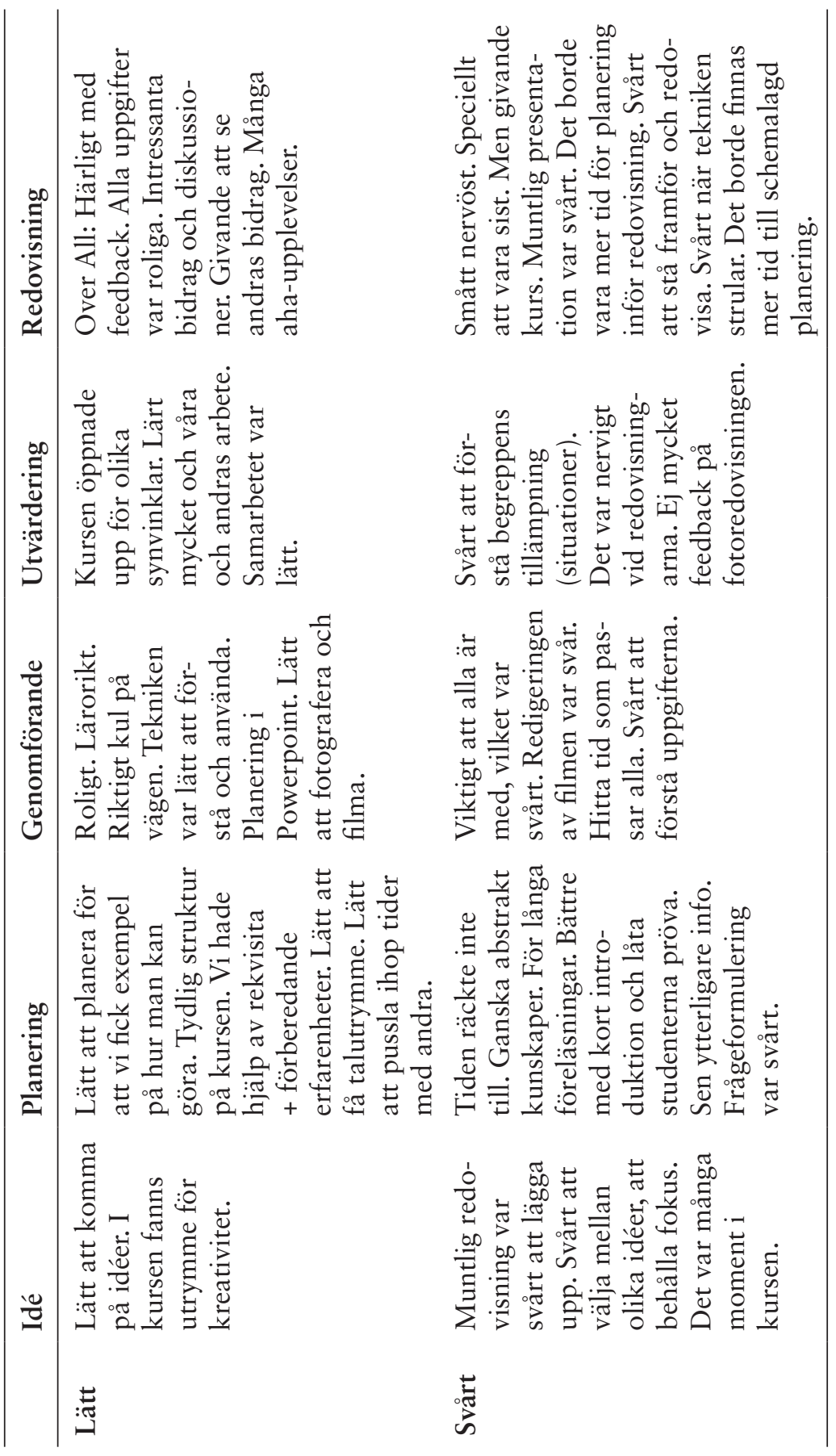


Lätt att komma på idéer. I kursen fanns utrymme för kreativitet. Det var lätt att planera för att vi fick exempel på hur man kan göra. Tydlig struktur. Vi hade hjälp av rekvisita + förberedande erfarenheter. Lätt att få talutrymme och att pussla ihop tider med andra. Genomförande: "Roligt! Lärorikt! Riktigt kul på vägen.” Tekniken var lätt att förstå och använda. Planering i Powerpoint var lätt och det var lätt att lära sig fotografera och filma. Over all: Härligt med feedback. Alla uppgifter var roliga. Intressanta bidrag och diskussioner. Givande att se andras bidrag. ”Många aha-upplevelser."

Muntlig redovisning var svårt. Tiden räckte inte till för planering. Ganska abstrakta kunskaper. För långa föreläsningar. Bättre med kort introduktion och låta studenterna pröva. Sen ytterligare info. Konstruera frågeformuleringar var svårt. Genomförande: Viktigt att alla är med, vilket var svårt. Att redigera filmen var svårt. Det var också svårt at hitta tider som passar alla och även att förstå uppgifterna. Utvärderingen av kursen: Svårt att förstå begreppens tillämpning (situationer). Det var nervigt vid redovisningarna. Ej mycket feedback på fotoredovisningen. Redovisning av kursen: Smått nervöst. Speciellt att vara sist. Men givande kurs. Muntligpresentation var svårt. Det borde finnas mer tid för planering inför redovisning. Svårt att stå framför och redovisa. Svårt när tekniken strular. Det borde finnas mer tid till schemalagd planering.

\section{Slutnoter}

I. Sparrman, 2006:23-30. Barns visuella kulturer: skolplanscher och idolbilder; Carlsson \& Koppfeldt, 2008_I6-33. Visuell retorik: bilden i reklam, nybeter och livsstilsmedia.

2. Waern, Pettersson, \& Svensson. 2004:176-180. Bild och föreställning - om visuell retorik

3. Lundahl, C. 20I I:9-16 \& I65-I68. Bedömning för lärande.

4. Lundahl, C. \& Folke-Fichtelius. M. 20II: I3I-I39 \& 305-307. Bedömning $i$ och av skolan - praktik, principer, politik. 


\section{Referenser}

Lundahl, C. 20 I I. Bedömning för lärande. Stockholm: Norstedts

Lundahl, C. \& Folke-Fichtelius. M. 20I I. Bedömning i och av skolanpraktik, principer, politik. Lund: Studentlitteratur.

Sparrman, A. 2006. Barns visuella kulturer: skolplanscher och idolbilder. Lund: Studentlitteratur AB; Carlsson, A \& Koppfeldt, T. 2008. Visuell retorik: bilden i reklam, nyheter och livsstilsmedia. Malmö: Liber.

Waern. Y, Pettersson. R, Svensson. G. 2004. Bild och föreställning om visuell retorik. Lund: Studentlitteratur. 
